\title{
Interview with Paul W. Kruse on the Early History of HgCdTe, Conducted on October 22, 1980
}

\author{
MARION B. REINE ${ }^{1,2}$ \\ 1.-Photon Detector Physics, LLC, Cambridge, MA 02138, USA. 2.-e-mail: marion.reine@ \\ comcast.net
}

This paper presents an interview with Dr Paul W. Kruse (1927-2012) on the early history of the semiconductor alloy mercury cadmium telluride ( $\mathrm{HgCdTe}$ or $\mathrm{Hg}_{1-x} \mathrm{Cd}_{x} \mathrm{Te}$ ) at the Honeywell Corporate Research Center near Minneapolis, Minnesota. Conducted on October 22, 1980, the interview covers two main areas. One area is the story of how the $\mathrm{HgCdTe}$ research effort came about at the Honeywell Research Center in the early 1960s, what technical choices were made and when, and what technical challenges were overcome and how. The other area is the organization, culture, environment and personnel at the Honeywell Research Center that made the early $\mathrm{HgCdTe}$ research programs so successful. HgCdTe has emerged as the highest-performance, most widely applicable infrared detector material. HgCdTe continues to satisfy a broad variety of advanced military and space applications. It is illustrative to look back on the early history of this remarkable semiconductor alloy to help to understand why its technological development as an infrared detector has been so successful.

Key words: Mercury cadmium telluride, $\mathrm{HgCdTe}$, infrared detector, semiconductor, history of infrared detectors

\section{INTRODUCTION}

The early history of HgCdTe in the late 1950s and early 1960 s was the subject of several invited papers presented at the special session "HgCdTe: 50 Year Anniversary Session", which was part of the SPIE symposium in April 13-17, 2009, at Orlando, Florida. ${ }^{1-4}$ Relevant historical details are also contained in a chapter by Ernest Putley ${ }^{5}$ in the 1999 book Cold War, Hot Science: Applied Research in Britain's Defence Laboratories 1945-1990.

The first publication on the synthesis of the narrow-gap semiconductor alloy mercury cadmium telluride ( $\mathrm{HgCdTe}$ or $\mathrm{Hg}_{1-x} \mathrm{Cd}_{x} \mathrm{Te}$ ) was a 1959 paper from the group at the Royal Radar Establishment (RRE) in Malvern, England. ${ }^{6}$ This seminal paper reported both photoconductive and photovoltaic response at wavelengths extending to $12 \mu \mathrm{m}$, and made the understated observation that this material showed promise for intrinsic infrared detectors.

(Received December 3, 2014; accepted March 6, 2015; published online April 15, 2015)
This group filed a patent in $1957 .^{7,8}$ However, as Tom Elliott (Dr Charles Thomas Elliott, FRS, CBE) recounts, ${ }^{2}$ despite promising initial $\mathrm{HgCdTe}$ results and their implications for thermal imaging, the British government shut down the HgCdTe effort at RRE by April, 1958 because the solid state physics resources at $\mathrm{RRE}$ were needed for work on InSb to replace $\mathrm{PbS}$ in the more urgent application of infrared guidance and homing for missiles.

In 1960, Dr Paul W. Kruse (1927-2012) (Fig. 1) was working at the Honeywell Corporate Research Center in Hopkins, Minnesota, on an internallyfunded program with the objective of realizing a new detector material for the 8-14 $\mu \mathrm{m}$ thermal imaging waveband that would have high sensitivity and enable operation at $77 \mathrm{~K}$. There was an urgent need to find a high-operating-temperature replacement for the 8-14 $\mu \mathrm{m}$ mercury-doped germanium detector, which had to operate at $30 \mathrm{~K}$ or lower. Through discussions with his Honeywell colleagues, including John Blakemore, and through research he was concurrently doing for his book Elements of Infrared 


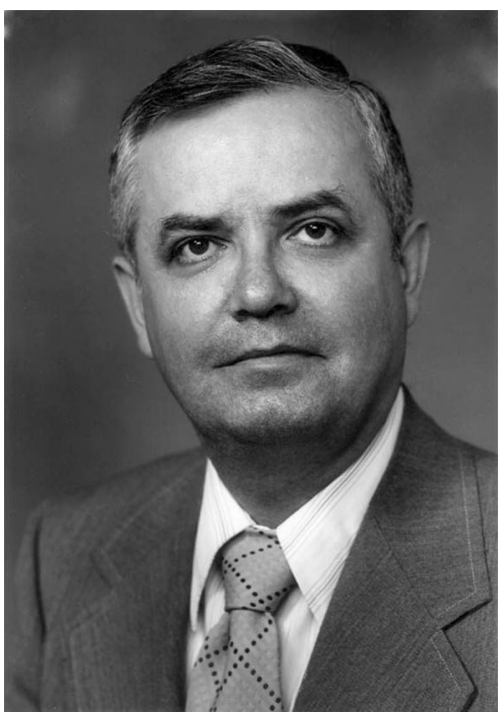

Fig. 1. Dr. Paul W. Kruse (1927-2012) received a PhD in Physics from the University of Notre Dame in 1954. He joined the Honeywell Corporate Research Center in 1956, where he began his pioneering work in $\mathrm{HgCdTe}$ in 1960.

Technology ${ }^{9}$ Paul knew the key characteristics that such a new material must have, namely an energy band gap of $0.1 \mathrm{eV}$ together with a band structure that featured the direct transitions necessary for high optical absorption and long excess carrier lifetimes. In a competitive procurement in which there were 30 proposals, Paul wrote and submitted the winning proposal to the Air Force Avionics Laboratory at Wright-Patterson Air Force Base, Dayton, Ohio, for development of a 8-14 $\mu \mathrm{m}$ photon detector operating at $77 \mathrm{~K}^{10}$

In his chapter (Ref. 5, page 201) Putley acknowledges the early success in HgCdTe by the Honeywell team: “...Minneapolis-Honeywell made the startling claim that they had succeeded in making CMT detectors with adequate performance at the relatively high temperature of $77 \mathrm{~K} . . . "$ On the same page he writes: "Because they had persisted with research on CMT, Minneapolis-Honeywell were now able to reveal that they had succeeded in manufacturing liquid-nitrogen-cooled 8-13 $\mu \mathrm{m}$ detectors." The British effort resumed their HgCdTe effort at RRE around 1966.

Paul and the Honeywell HgCdTe team devised a modified Bridgman crystal growth technique for HgCdTe. They soon reported, in 1962, key characteristics of the $\mathrm{HgCdTe}$ alloy and both photoconductive and photovoltaic detection by use of rudimentary HgCdTe devices. ${ }^{11,12}$ In 1964 they succeeded in demonstrating the first high-quality LWIR HgCdTe photoconductive detectors, having a blackbody detectivity, $D^{*}{ }_{\mathrm{BB}}$, of approximately $2 \times 10^{9} \mathrm{~cm}$ $\mathrm{Hz}^{1 / 2} / \mathrm{W}$ and operating at $77 \mathrm{~K}$. The initial Honeywell $\mathrm{HgCdTe}$ team included Don Blue, Jim Garfunkel, Charlie Butter, Bernice Johnson, and Warren Saur. Joe Schmit, Don Long, Ernie Stelzer, Paul Petersen, Obert Tufte, Chuck Speerschneider, and Walter
Scott joined the rapidly expanding HgCdTe effort later in the $1960 \mathrm{~s}$.

In 1965, this embryonic yet highly promising HgCdTe detector technology began to be transferred to the Honeywell Radiation Center, an operating division of Honeywell located in Lexington, Massachusetts. The Radiation Center was able to insert early $\mathrm{HgCdTe}$ photoconductive detectors into military and space applications that were urgently seeking an 8-14 $\mu \mathrm{m}$ detector with high sensitivity and able to operate at $77 \mathrm{~K}$. Honeywell maintained two parallel efforts in $\mathrm{HgCdTe}$ detector science and technology, one at the Research Center and the other at the Radiation Center, until around 1980 when the effort at the Research Center was discontinued. The Research Center focused on $\mathrm{HgCdTe}$ materials science and new growth techniques ${ }^{4}$ whereas the Radiation Center focused on $\mathrm{HgCdTe}$ detector product development and insertion into infrared sensors. ${ }^{3}$

In 1980, I interviewed Paul Kruse on his recollections of the early history of the development of HgCdTe. The two-hour interview was conducted in my office at the Honeywell Radiation Center in Lexington, Massachusetts, on October 22, 1980. The resulting cassette tapes lay in one or another of my desk drawers for the next 33 years, until the spring of 2013 when I wrote and presented a memorial paper $^{13}$ (see also Ref. 14) on Paul Kruse's career for the 2013 SPIE meeting in Baltimore. I reduced the length of the original interview by about a third and eliminated some material that, although quite interesting in its own right, was not relevant to the topic. This paper presents the text of that interview. With only a few exceptions, the words are those of Paul Kruse taken directly from the tapes.

Two main areas were covered in this interview. One has to do with story of how the early $\mathrm{HgCdTe}$ research effort came about, what technical choices were made and when, and what technical challenges were overcome and how. The other has to do with the organization, culture, environment, and personnel at the Research Center that made the $\mathrm{HgCdTe}$ research programs so successful in the early 1960s.

This interview parallels the historical recollections of the early development of $\mathrm{HgCdTe}$ at Honeywell that are contained in a commentary written by Paul Kruse, probably ca 1980 , which was published as Appendix C of Ref. 13.

Both the Honeywell Corporate Research Center in Hopkins, Minnesota and the Honeywell Radiation Center in Lexington, Massachusetts underwent name changes and other changes in the years just before and subsequent to this 1980 interview, but in this paper they are simply and consistently called the Research Center and the Radiation Center. The Research Center moved from Hopkins, Minnesota to Bloomington, Minnesota in 1972.

My questions to Paul are shown in italics. Paul referred to several papers during the interview. I inserted reference numbers in the interview text, and the papers are listed in the References section. 


\section{INTERVIEW}

\section{The Beginning of HgCdTe at Honeywell}

REINE: How did the HgCdTe work start at Honeywell, and when? You were there at the beginning.

KRUSE: In about 1960 we began, at the Honeywell Research Center in Hopkins, Minnesota, an internally-funded research effort to look for an 8-12 $\mu \mathrm{m}$ intrinsic infrared detector working at liquid nitrogen temperature, to look for a material that would be suitable for that. The state-of-the-art was such that 8-12 $\mu \mathrm{m}$ detectors were desired for airborne earth-mapper systems. But there was no material that worked at liquid nitrogen temperature. There were doped germanium detectors, for example mercury-doped germanium was the most useful one, that worked in the 8-12 $\mu \mathrm{m}$ region, but that operated at below $30 \mathrm{~K}$

There was a zinc-doped germanium detector called a ZIP, zinc impurity photoconductor, that was developed at the Naval Research Laboratory. That was a $40 \mu \mathrm{m}$ detector, operated at $4 \mathrm{~K}$. There was copper-doped germanium, which went out to $25 \mu \mathrm{m}$. Then mercury-doped germanium was developed, and mercury-doped germanium was most useful because it worked in the 8-12 $\mu \mathrm{m}$ region, didn't go out much further than that in wavelength, and therefore had the highest operating temperature, which was $30 \mathrm{~K}$.

The mercury impurity in germanium was first experimented with at Syracuse University in Professor Henry Levinstein's group.

I wouldn't be surprised, a lot of that stuff was done there.

Seb Borrello ${ }^{15}$ measured the activation energy of mercury-doped germanium and found it to be suitable. But because all of Henry's work was funded by the air force, they were also concerned with practical applications, and 8-14 $\mu \mathrm{m}$ was certainly one of them.

Then, if you look at it from the other point of view, from an intrinsic detector, operating at liquid nitrogen temperature, what was available at the time was lead selenide, and some work on lead telluride...lead telluride never was as good as lead selenide, but that was also a $3-5 \mu \mathrm{m}$ detector. And then the thing that had come along in the 1950s was indium antimonide. Indium antimonide at that time was the best $3-5 \mu \mathrm{m}$ material. The best intrinsic material was indium antimonide because that was a true single-crystal semiconductor, whereas the lead salts were all polycrystalline, difficult to understand the carrier transport and recombination mechanisms in them. So you had the 3-5 $\mu$ m intrinsic liquid nitrogen temperature detector, you had the 8-12 $\mu \mathrm{m}$ extrinsic $30 \mathrm{~K}$ detector. We obviously wanted the combination of the two, the intrinsic 8-12 $\mu \mathrm{m}$ detector.

Was it clear, before you started to look for this detector material, that you could get 8-12 $\mu$ m background limited infrared photodetector (BLIP) detection at temperatures around 77 Kelvin?

Yes. The BLIP theory had been underway. There had been people that had looked at the background limit, including myself. It was understood that, from that point of view alone, it should be possible to get 8$12 \mu \mathrm{m} 77 \mathrm{~K}$ operational. Although that didn't tell anything about the material; that just told you that if, say, operating in the photoconductive or the photovoltaic mode at liquid nitrogen temperature, you could achieve a real high $D^{*}$ in the 8-12 $\mu \mathrm{m}$ region.

There was a general appreciation of the fact that intrinsic detectors required less cooling than extrinsic. Although that wasn't really quantified until about 1968, by my Honeywell colleague Don Long. There were two articles that he wrote, ${ }^{16,17}$ and he was the one that quantified it. But there was a general appreciation of the qualitative aspect of it then, that extrinsic detectors required more cooling.

\section{Early Infrared Detector Research Efforts and Personnel at Honeywell Research Center}

And, of course we had worked on indium antimonide at the Research Center. Actually that started with work I did on the photoelectromagnetic (PEM) cell when I first went there in 1956. I had met a fellow by the name of I.M. Ross, ${ }^{18}$ I think it was, who had visited IT\&T where I had worked previously and brought around a PEM cell, an indium antimonide PEM cell, and it was quite fascinating. And so, when I got to Honeywell, basically my first research project was to... I went to work for Don McGlauchlin... was to develop an indium antimonide PEM detector. Don and I just decided casually that would be a nice thing to work on, because he was building up an infrared detector group.

Who else was in the infrared detector research group at that time?

Well, Rich McQuistan. Rich McQuistan and Don McGlauchlin and I and Frank Simon had all come from IT\&T. It was called Farnsworth, and then it was called Capehart Farnsworth, and then Farnsworth Electronics, and then IT\&T, and we'd all been there. We all came to Honeywell at different times, but during the year of 1956 we all came, first Don and me, then McQuistan and then Simon. We'd all been in the same group back at Farnsworth, back at IT\&T. So we knew about lead telluride detectors, we had worked on them. When he got to Honeywell, Don McGlauchlin started working on lead telluride.

\section{Early Effort in Indium Antimonide Infrared Detectors at the Research Center}

And then I started on indium antimonide. Indium antimonide and the III-Vs were not very old at the time. There was this paper by a German fellow, Herman Welcher. He had shown in 1952 that the III-Vs were semiconductors, and he began to synthesize them. Mostly the ones he looked at, if I recall correctly, were indium antimonide and indium arsenide. In fact, he patented the III-Vs. He's got the famous Welcher patent that nobody pays attention to, but everybody that makes a gallium arsenide device violates the Welcher patent. Westinghouse 
tried to collect money from everybody; they were the licensee in United States. Nobody would pay them anything for it.

But we started working on the PEM cell first. That meant we had to grow indium antimonide. We had pure indium and pure antimony, and we did a Czochralski growth, and we did zone refining on one of the materials.

Then that became a Honeywell product, the indium antimonide PEM cell, and I did that. ${ }^{19}$ Well, then Charlie Butter and Don McGlauchlin, I think, began working on a photoconductive indium antimonide detector, which was about 1958 or 1959 . They went to zone leveling crystal growth if I recall, and that was successful. The Honeywell Radiation Center in Lexington, Massachusetts, had a contract with HRB Singer (Haller, Raymond and BrownSinger) to deliver a single element, indium antimonide photoconductive detector for the mapper that went in the army Mohawk aircraft. ${ }^{3}$

I'm jumping ahead a little bit when I talk about the indium antimonide photoconductive detector manufacturing that went into the mapper. But the reason I say that is that it laid the ground work for the Honeywell Radiation Center later on, in getting contracts with HRB Singer to substitute LWIR photoconductive mercury cadmium telluride for MWIR photoconductive indium antimonide.

\section{Early Research on Tellurium at the Research Center}

So Don McGlauchlin and Charlie Butter were working on the photoconductive indium antimonide, and also were looking at photoconductivity in tellurium because we were growing tellurium at the laboratory too.

At our laboratory at that time, there was a lot of interest in tellurium, and we were the foremost growers of tellurium. That wasn't the department that I was in, that was the department that had John Blakemore and Allen Nussbaum and some other people, and a fellow by the name of Tom Davies $^{20}$ who was our crystal grower for the laboratory. He managed to grow tellurium crystals in largediameter ingots by, I think, Czochralski, and prior to that people had just been growing tiny crystals by a Bridgman process or something. Honeywell at that time had become the foremost in the world, I believe, in growing crystals of tellurium. ${ }^{21}$

What was the interest in tellurium then? Was it infrared detection or basic research?

No, it was not infrared detection, but basic research. People were interested in tellurium because its electrical properties were not isotropic, and it was a new semiconductor material. After all, at that time you really only had germanium, and people had hardly started to work on silicon, a little bit. Then the
III-Vs, and that was it. Well, here's tellurium... another material.

\section{Origins of the Infrared Detector Research Group at the Research Center}

How did Don McGlauchlin come to set up an infrared detector group at the Research Center?

First, Don McGlauchlin had been a manager of a vacuum tube lab at IT\&T. He had a large group of people reporting to him doing development and manufacturing. The tubes were image converters and high-current photomultipliers and things like that. He was hired by the Honeywell Research Center in April of 1956, April or May, into a group at that time that was called Primary Sensors. The idea was to develop sensors, radiation being one type of sensor, but pressure... what have you. The man that was head of that group hired Don and hired me, and quite soon he left the lab.

Don McGlauchlin became the manager of the department, and it was still Primary Sensors, and we were looking at things other than radiation detection. But my background was in radiation detection, and the other sensors kind of fell by the wayside. As McQuistan came into it, within a year or so it was primarily infrared detection technology.

So in the absence of some strong divisional thrust, this infrared group developed out of a general interest, a corporate interest in sensors?

Yes.

Mainly because of the people they hired more than...

Yes. It was a "bottoms up" effort rather than a "tops down."

Finn Larsen was the Director of Research. Prior to 1954, when people like Don Long and Karl Nomura, John Blakemore, and Allen Nussbaum were hired, the Research Center was sort of an engineering group, and there weren't any scientists as such, and there were just a few engineers. Then Finn Larsen came and began to look for people with PhDs who were scientists, particularly solid-state people, and so he hired that group and then it expanded. Since they had no history at all, they were trying to do some very good scientific research and at the same time began to think about some potential products for the company.

Incidentally, at that time Honeywell owned a division, the Semiconductor Products Division down in Riviera Beach, Florida, and they were manufacturing germanium transistors. The germanium work had originally been done at the Research Center by Nussbaum, Blakemore, Nomura, and Long. They were standing in support of the Riviera Beach division, and Riviera Beach was making germanium power transistors and was sort of the foremost company to do that, but they were never a successful business enterprise. 


\section{Internally Funded Research Project for an Intrinsic 8-12 $\mu \mathrm{m}$ Infrared Detector Operating at $77 \mathrm{~K}$ Began in 1960}

About 1960, then, I started a research project, which I referred to at the beginning of this interview, to look for an intrinsic 8-12 $\mu \mathrm{m}$ material. We also appreciated at that time that you'd like to have a direct gap semiconductor.

As opposed to germanium, which is indirect gap. Why was that?

We went through this analysis of lifetime in our book, ${ }^{9}$ which was being written at the same time, Elements of Infrared Technology by Rich McQuistan, Don McGlauchlin and myself. I wrote the last half of the book, the last five chapters. There I was looking into the theoretical concepts for radiation detection and trying to understand this competition between various recombination mechanisms, and talking with John Blakemore, maybe the world's expert in lifetime in semiconductors.

Was Blakemore's book already written at the time?

He was writing it or just had... it was published in $1962 .^{22}$

Through him being there, with all the lifetime measurements he was making and the analysis he was making and so on, we were getting an appreciation of the fact that there are different lifetime mechanisms, like Auger. We were one of the first ones to talk about Auger recombination.

We find that, in the book, the competition between Auger and radiative lifetime. Of course, we didn't want a Shockley-Read type of mechanism, we would like to have really a fundamental mechanism. You will see a chapter in the book ${ }^{9}$ where there is a hypothetical 8-14 $\mu \mathrm{m}$ intrinsic material and there is a figure in there that shows the lifetime as a function of temperature, for both $n$ and $p$ type, for both radiative and Auger lifetime (Chapter 9, Figs. 9.18 and 9.19, pp. 380-381). Going from room temperature to $77 \mathrm{~K}$ or something like that, maybe a little below $77 \mathrm{~K}$. I made some of those calculations and Blakemore made some, I don't remember exactly.

Once you know the lifetime mechanisms then you can predict what the noise would be, and then you can see the noise essentially begin to compete with background noise, and then develop a criterion for BLIP.

There was a general feeling that, in order to get to the BLIP limit at the highest operating temperature, you should have the dominant recombination mechanism be radiative, that was a general feeling. That had come out of this paper by Petritz ${ }^{23}$ back in 1954, or maybe it was a 1959 issue of the Proceedings of the IRE. There's a Photoconductivity Conference volume in 1954 which had the Rittner paper $^{24}$ in it, and I think Petritz had a paper ${ }^{25}$ in it too, and there was the 1959 issue of the Proceedings of the IRE. Between those two, people were beginning to get an appreciation of how detectors really worked and how to optimize them. So then, we started the project then in about 1960, I think.
So the question was, how could you get an 8-12 $\mu \mathrm{m}$ direct gap material. So then it switches from a theoretical point of view to a materials point of view.

\section{Candidates for a Semiconductor with a 0.1 eV Direct Bandgap}

The candidate materials at that time were mercury selenide... which was our first choice..., mercury telluride, an alloy of indium antimonide and indium arsenide, grey tin, a ternary called copper iron telluride, I think $\mathrm{CuFeTe}_{2}$, and so on. There was magnesium tin-magnesium lead $\mathrm{Mg}_{2} \mathrm{Sn}-\mathrm{Mg}_{2} \mathrm{~Pb}$. And of course mercury cadmium telluride.

And other candidates were thallium antimonide and indium bismuth, and also an alloy of thallium antimonide and indium bismuth.

How did we get at these? Well, take them one at a time. There were some literature reports on mercury selenide that indicated it was a tenth of an electron volt semiconductor, there was just one paper in the literature or something. There was another paper in the literature that indicated that mercury telluride had an energy gap of $0.02 \mathrm{eV}$. In other words, $20 \mathrm{meV}$, one paper on that. Very little in the literature.

And of course the band structures of both of these materials were still unknown?

Completely unknown band structures.

We weren't the only people, incidentally, that were looking for this. There was an army contract with Battelle, and there was a navy contract with Eastman Kodak, and they started about the time we got our air force contract, which I'll get to in a little bit. The magnesium tin-magnesium lead alloy work was done at Battelle, because there had been some indication that that was a small-gap material. Small gap by definition at that time was like a tenth of an electron volt. There was some indication that that material was a semiconductor.

That ternary I mentioned, like copper iron telluride I think it was, that came out of one of Henry Levinstein's reports. Henry Levinstein was writing annual reports on his air force contract. In one of them about that time, he had this list of candidate, small gap materials, semiconductors that might be useful for infrared detection, and somewhere he got this idea of copper iron telluride. When I asked Henry about it later, he wasn't sure where it came from. I think it came from the Russians. Maybe from a Russian paper translated by the American Institute of Physics (AIP). Henry had in the table that it had a tenth of an electron volt.

Now, the indium-bismuth-thallium-antimony alloy was a rather obvious thing when you go down the III-Vs. We knew in general that you'd like to be close to the center of the periodic table because the III-Vs are covalently bonded, but the II-VIs and I-VIIs were generally ionic bonded. There was a 
feeling that you wanted to have a covalent material. So it was rather obvious.

We looked at thallium-bismuth too.

So that was a candidate. Then there was the indium arsenide-indium antimonide alloy. There was a report in the literature that when you made the alloy of those two materials, the energy gap, instead of lying between them, went to a minimum at some intermediate point. It was reported that the long-wavelength limit would be like $8 \mu \mathrm{m}$ or $9 \mu \mathrm{m}$.

So when we looked this list over, what did we start working on? Here, I'm not exactly sure which part was done under the contract and which was done not under the contract, prior to the contract.

Is this 1960 or earlier?

This was 1960 .

\section{Honeywell Research Center Wins an Air Force Contract to Develop an Intrinsic Semiconductor Detector with a $0.1 \mathrm{eV}$ Bandgap Operating at $77 \mathrm{~K}$}

Let me jump ahead a little bit. Late in 1960, maybe October or something like that, the air force came out with an RFP to do exactly what we had intended to do under our in-house efforts. Exactly the same requirements: $8-12 \mu \mathrm{m}$ intrinsic infrared detector operating at the highest possible temperature, hopefully liquid nitrogen temperature.

When the RFP came out, we had been working 3-6 months on this project. It was a competitive procurement. I was told later there were $30 \mathrm{com}$ panies bidding. We obviously wrote the winning proposal. It had a lot of this theoretical analysis. It had a list of candidate materials. It had a lot of the theoretical analysis as why you might expect an 8-12 $\mu \mathrm{m}$ detector to work. I was the proposal manager and other people worked on it.

That contract began in February of 1961. Air force contract 33616-7901. Thad Pickenpaugh was the contract monitor.

How did the air force get the idea for the RFP, do you think? Was it Thad's idea, or was it someone else?

They were interested in mappers. I think they supported the mercury-doped germanium work, which Texas Instruments was doing. Maybe some other places, too. Henry Levinstein had done the original development on mercury-doped germanium. The air force had been supporting Henry all along. So the air force was interested in detectors. They went out to industry for this contract.

We won the contract. I can't remember exactly when we actually started growing materials, whether it was right at the beginning of the contract or whether we already started the in-house materials growth efforts just before we won the contract.

\section{HgSe and HgTe were the First Two Candidates Looked at Experimentally}

Somewhere around the first of 1961 we began to work on mercury selenide. I think it was before we got the contract. Don Blue was working with me on the contract, and I think Charlie Butter or Jim Garfunkel. We grew crystals of mercury selenide, and began to measure their electrical properties and look for an absorption edge. We put them in a spectrometer and looked for an absorption edge and looked for photoeffects. What we found was that the samples were $n$-type. We measured the Hall coefficient as a function of temperature for different samples. They were highly opaque, out to $14 \mu \mathrm{m}$, maybe even farther, I can't remember how far out we looked. We got photoeffects. We looked at both photoconductivity and the PEM cell.

About that time, I got these photoeffects and they were suspicious from a variety of points of view. You could get a PEM signal and you could get a photoconductive signal, except that I began to worry about thermal effects because they had a fairly lowfrequency roll off. Of course, we had expected about a microsecond or so from our experience with indium antimonide and from this idea of radiative lifetime and what it should be. Instead, we were getting like a millisecond, which was very unusual.

I then considered what thermal effects you could get, that would give rise to a voltage. I found that if you just looked at it fairly simply, in the PEM configuration, that was also the same configuration for a Nernst effect, a thermally excited Nernst effect. And in the photoconductive configuration, that was also the same configuration for a bolometric effect. It was great to get the photosignals, great to get Hall effect data, but we were a little bit suspicious.

Don Blue and I analyzed it and wrote a paper, ${ }^{26}$ which was published in Journal of Physics and Chemistry of Solids, on the electrical properties. Blue, Garfunkel and I published a second paper ${ }^{27}$ in Journal of the Optical Society of America. There, we began to consider mercury selenide to be a degenerate semiconductor. The photoeffect data we explained in terms of thermal effects rather than true photon excitation.

Our second choice was mercury telluride. Mercury telluride was similar to and just about as easy to grow as mercury selenide. That was thought to be a $0.02 \mathrm{eV}$ semiconductor. We grew some mercury telluride. I'm sure we did. That was worse than the mercury selenide in terms of the number of free electrons at any given temperature, but you could get nominally photoeffects out of it, which at that time we were convinced were thermal effects. Very quickly, we decided that mercury telluride was a semi-metal also. 
Somewhere along the line, we looked at, for a short time, indium bismuth and thallium antimony, and also the alloy of indium bismuth and thallium antimony. We were doing crystal growth at the time. I think Tom Davies was doing it. The problem with those materials was that they didn't form any kind of compounds. We didn't spend a lot of time, but when we would react indium with bismuth, we'd get an ingot that had indium in it and had bismuth in it, but no reaction products. Maybe, if you work at it for a long time, you could solve that problem. I don't know. The same with the thallium antimony. It just didn't react. So we abandoned that.

\section{Attention Shifts to HgCdTe}

After looking at mercury selenide and mercury telluride, we decided we wanted to work on mercury cadmium telluride. The reason we decided that was that there was a paper ${ }^{6}$ in the literature, the famous one by Lawson, Nielsen, Putley, and Young published in Journal of Physics and Chemistry of Solids in 1959, that indicated that mercury cadmium telluride was a semiconductor, at least over part of the composition range. They had a plot in their paper that showed the energy gap as a function of the alloy composition parameter $x$, where $x$ is the fraction of cadmium telluride in the alloy. I don't remember what temperature it was for. In fact, I'm not even sure they specified the temperature. From that, it looked like you wanted to have a $10 \%$ alloy, that is, $10 \%$ cadmium telluride, $90 \%$ mercury telluride. That would get you a tenth of an electron volt.

Obviously, it was a fairly complicated material to work with because of the problem of explosion. You knew right away, that when you're working with mercury, first of all, it's hard to work with. You knew right away that you couldn't heat it up in an open tube. Second, that even if you put it in some sort of ampule it explodes.

I can't remember the indium-bismuth-thalliumantimony approach. I don't remember just exactly where we had that on the list.

We wrote a letter to Thad Pickenpaugh. ${ }^{14} \mathrm{We}$ were writing contract reports. Maybe it was in the contract report or maybe it was a letter. We listed eight or ten candidate materials. We'd already looked at the first two. We wanted to start working on mercury cadmium telluride. We got a letter back from the air force to the effect that they didn't want us to work on mercury cadmium telluride, because that was already under investigation by the British.

So I talked to whoever it was that was doing our contract marketing at the time. He wrote a formal legal-type of letter back to Thad, or the air force, or whoever it was, saying that we would not be responsible for the technical success of the contract unless we could pick our materials of choice. And then the air force wrote back, and they said that's fine. Go ahead. So our third material was mercury cadmium telluride.

\section{HgCdTe Growth Effort Began in Early 1962}

So we began to grow mercury cadmium telluride around the beginning of 1962 .

Now, there was some general interest in mercury cadmium telluride at other places at the time. My recollection was a fellow at Eastman Kodak, whose name I think was Don Morey. ${ }^{28}$ He had worked on the lead sulfide detectors at Eastman Kodak. Don Morey had tried to evaporate mercury cadmium telluride, because that's the way he was making lead sulfide, by evaporation. He had a navy contract that he worked on during the early $1960 \mathrm{~s}$. He was entirely unsuccessful in terms of any kind of good results. He was trying to evaporate mercury cadmium telluride, if I recall correctly.

The Battelle group, the army effort, was working on magnesium-tin, magnesium-lead alloy, I think. We, under the air force contract, were working on mercury cadmium telluride by bulk crystal growth. There was some effort at the MIT Lincoln Laboratory at the time by Alan Strauss and Ted Harmon, I believe. At least Ted was involved, and I think Alan was, too. I'm not sure that they were interested in it at the time for infrared detectors. Alan had been at Chicago Midway Laboratories around 1956, 1957. He was growing indium antimonide there. He was looking at photoeffects in it, I think, studying the semiconducting properties of it, not interested in a detector per se though. Then he went to MIT Lincoln Laboratory and started working with Ted Harmon. They were generally interested in mercury cadmium telluride, and were trying to grow crystals of it.

I think there was some other work going on, too. I think the French work had started about the time we did, too. Madame Verie and coworkers.

There were also some early Polish papers in the early '60s talking about mercury cadmium telluride.

About 1960 or 1961, the American Institute of Physics (AIP) began to translate the Russian journals. And by gosh, there were a lot of Russian papers. By a lot I mean maybe half a dozen of them on mercury cadmium telluride. But, they never went to a small gap composition. Their compositions that they reported in their scientific journals were always about $70 \%$ and up. They were looking at photoresponses in the $1-2 \mu \mathrm{m}$ region. I presume it was for security considerations that they didn't report their other work. I can't imagine they didn't work on it for the same reason we did.

We began to try to grow mercury cadmium telluride crystals. We started out right away by having to put them in a sealed ampule, a quartz ampule. I think we started out right away with a $12.7 \mathrm{~mm}$ inner diameter. I called it at the time a modified Bridgman method. What we were trying to do was to drop the crystals slowly, at a very slow lowering rate, through a very steep temperate gradient, because we knew about the problem of constitutional supercooling. I think that Harmon and Strauss were talking about this at the time, or somebody else, in 
general terms, not specifically for mercury cadmium telluride. It was important to lower the crystal very slowly through a very steep temperature gradient. Otherwise, you had a bi-stable phenomenon in which you could get two different $x$-values freezing out. That would give rise to a dendritic structure. That was called constitutional supercooling. We realized you had to get a very steep temperature gradient and a very slow growth rate. So we were dropping the crystals through a freezing plane.

These had already been compounded?

Yes, my recollection is, we started right from the very beginning with the rocking furnace idea for compounding. We would compound it in an ampule. Then we would take that ampule out of that furnace after it came back down to room temperature. We would have an ingot in there. But it was polycrystalline. Then we would try to drop it through a freezing plane in a vertical furnace, a Marshal Products furnace. We even went so far as to actually have at the very bottom of the furnace a pool of water. Maybe it was oil. Anyway, it was some liquid that was at room temperature. The ampule would actually lower into that.

There was also the idea of freezing from a large volume. That idea was in the literature. Ted Harmon was trying to follow that procedure. I can't remember what the paper was at the time. We knew of course that we wanted to get a uniform $x$-value. We had some knowledge of the idea of the phase diagram and the fact that there was a solidus and a liquidus that were separate from each other, and therefore, that as you tried to freeze, you would segregate. We knew that general concept. We knew that therefore you just had a non-uniform composition along the longitudinally, to say nothing of laterally.

We looked into this whole business of freezing from a large volume, where the volume was so large that you could always replenish the excess cadmium in the first-to-freeze part. I think the idea was to make kind of a long, tall ampule, if I recall. We worried about the mixing. We worried about temperature distributions a lot. We bought a Marshal Products furnace that I think we had designed with a large number of taps on it, like 12, so with resistance elements or with Variacs we could profile the temperature within the furnace. We were very concerned about getting the steep temperature gradient. We had models for heat transfer through the quartz tube and up the liquid and solid. We got into that a lot.

Very quickly, as soon as we began to make the material, even though the material wasn't very good quality, we began to look at photoeffects. We began to see them. I fact, we saw some that extended past the $8-12 \mu \mathrm{m}$ region.

We were measuring absorption edges, and they were very, very strange. They had all sorts of nonsmooth shapes. That was due to the fact that the spectrometer looked at fairly broad region of the sample in which there was a varying composition.
But response times were short?

Yes. We wrote a paper in Infrared Physics in early $1962^{11}$ in which we talked about mercury selenide, mercury telluride, and mercury cadmium telluride. We talked about this competition between the thermal and photo mechanisms. We were able to show that in mercury selenide and mercury telluride, the only thing you got were thermal effects, but here in this work with mercury cadmium telluride, we got a true photon effect. We published that in 1962. That was just a little sample from one region of a crystal that happened to go beyond $12 \mu \mathrm{m}$, I think. Maybe it went to $14 \mu \mathrm{m}$ or $15 \mu \mathrm{m}$. That we did at helium temperature. We of course were doing resistivity and Hall also besides transmission. We were doing that down to helium temperature.

We were looking at photoconductivity. We had sort of abandoned the idea of looking at the PEM effect.

Then, because the electron mobility was so high, we began to worry about the $\mu B$ products (the product of the carrier mobility $\mu$ and the magnetic field strength $B$ ) and the way you looked at Hall coefficient data. You get magnetoresistance and you get a Hall effect. You had a field dependence of these parameters, which are nominally resistivity and Hall coefficient, which are nominally field independent. You had a field dependence in them. That dependence depended upon what the mobilities were and their ratio, and what the composition was. You had all these strange effects that were showing up when you began to take your Hall data. The Hall coefficient at low fields would be field independent and then start dropping. We were doing a lot of modeling to try to fit and estimate. We didn't know what the mobility values were or anything like that. You're doing it at various temperatures, and you're trying to fit these complicated models that had field dependencies in them.

Then, of course, we had these strange things for just the Hall effect in itself as a function of temperature. In $p$-type material, you had the double cross-over type of stuff. In $n$-type material, instead of just going up and flattening off, instead the Hall coefficient would go up to a peak, come down a little bit and go back up again. Real strange effects. So it was a very weird and complicated material we were working with.

\section{Explosions All the Time}

And then we had the explosions. Explosions all the time. We started out with our first furnace contained in a plywood box. Warren Saur was working as a technician on the thing at that time. We had one monstrous explosion that blew the plywood box apart at the screws. It was screwed together. It pulled the sheets apart. The darn mercury went all over the laboratory. This was in the basement of the old Research Center. Of course, the laboratory was contaminated with mercury. It took us about 2 weeks to a month to clean that out. It was just like entering 
Three Mile Island. You could go in there for a few minutes. When you did that, you'd raise a mercury dust. It was embedded in the paint and in the floor and all over. We had a mercury monitor just like radiation monitor. You'd go in there and then you'd start stirring up that dust, and the mercury monitor started to indicate a mercury concentration beginning to rise in there. You could do a little bit of cleaning, but then you had to get out.

After the explosion in the box, we went to this steel well-casing. Warren found the original container for the furnace. Incidentally, the ampules, I don't think originally were within a steel pipe within the furnace. That meant that you'd destroy the furnace when the thing went. These are the rocking furnaces I'm talking about. They were homemade, so we could rewind another furnace pretty quickly. But the whole thing was then put inside this big well-casing with the end plates. We vented it all the way up to the roof. So when one of them exploded, it would not destroy anything in the laboratory. The gas vapors would go out on the roof and presumably disperse around there.

\section{Photoeffects Seen Almost Immediately in $\mathrm{HgCdTe}$}

We got photoeffects almost immediately, from the first crystal, I think. Very exciting, because we had a black body set up there and we had a wave analyzer. You used the wave analyzer tuned to the chopper frequency. I can still remember seeing that first needle begin to pin when we opened the shutter. For the first good far-infrared detector, 8-12 $\mu \mathrm{m}$ detector, the needle went all the way over to the right. When we started turning the range switch, it was still all the way to the right, until we went a number of orders of magnitude. I think the first detector probably came just a few months after we started looking into mercury cadmium telluride.

Bernice Johnson had not gone to college, had no technical training, but she'd worked as a lab technician. She was a person who was really dedicated to whatever she worked upon. One of the things we noticed right away, when you cut into these ingots, was the fact that there was a color cast to them. She was able to associate the "good material" with a pinkish color. She could see it well and I could see it sometimes. Nobody else could see it. We tried to do reflection measurements to actually try to see that region in a spectrometer. We were never able to actually detect it, but there was very clearly a pinkish cast to it. So, Bernice very quickly got to know where the good material might be in an ingot.

Incidentally, we were looking for $10 \%$ material, because of the Lawson, Nielsen, Putley, and Young article. ${ }^{6}$ We weren't looking for $20 \%$. We didn't know that. We didn't know mobilities. We had these weird effects that had to with $\mu B$ products. That was really a difficult thing to work on. We originally thought we needed $10 \%$ material, but of course we were working with other compositions, plus the mercury cadmium telluride itself had a great variation.

We were trying to understand what the $x$-value actually was in a given piece. We were looking at $\mathrm{x}$-ray measurements, and trying to measure the lattice constant, and that was not very sensitive. There was this paper ${ }^{29}$ on density in the literature by John Blair and Roger Newnham. Maybe their paper was the first x-ray data. We tried to use electron beam microprobe analysis. We eventually came up with density as being the most reliable method of determining alloy composition. We had to get calibrations on all this. The whole thing was a very iterative procedure.

Once we started on the mercury cadmium telluride we pretty much concentrated on that, and as we began to get photoeffects that clearly extended through the $8-12 \mu \mathrm{m}$ region, we really saw we were on to something then.

Interestingly enough, the British had dropped their work on mercury cadmium telluride completely, ${ }^{2,5}$ and I talked to Putley, I think, about that later. He said, well, their original results were so negative and the doped-germanium looked so attractive that the English efforts switched over to, I think, mercury-doped germanium. They dropped their effort on mercury cadmium telluride, right after that paper apparently. I think that was their only paper $^{6}$ on it until later when they restarted their mercury cadmium telluride effort.

We were growing many, many ingots. We were measuring a lot of detector properties and we were reporting these results at the IRIS meetings. As soon as we got any kind of detection that looked at all promising, we got a confidential stamp on our work. We could not publish anything in the open literature on the photoeffects. I think we could still publish on the electrical properties. We began to give talks at IRIS meetings and write for Proceedings of IRIS. A lot of our earlier papers, maybe three or four of them, are not in the open literature. They're just in the IRIS proceedings. This would be the '62, '63, '64 time frame.

\section{Happy Accident in 1964}

Well, we have that one magic ingot, of course, 6-18-64, where we name them by the date on which they were compounded, June 18, 1964 in this case. We were growing 6-18-64 over the weekend. We had compounded it in the rocking furnace and put it in a Marshall Products furnace, which is a vertical furnace. We were trying to drop it through a steep temperature gradient.

Over the weekend, one of the Variacs burned out, and the upper part of the ingot was supposed to be molten. Instead it underwent a high-temperature anneal. By Monday morning, maybe half the ingot had gone through the freezing plane. The upper half, which had been previously compounded, because the Variac fuse had blown, the upper part of 
the ingot had not remained in the molten state. When we found this accident had happened, we took the ingot out and simply set it aside, and did not look at it anymore.

Later on in the year, it was 5 or 6 months later, Bernice Johnson said that she would like to take a look at that ingot. We had cut into it, I think, or something like that, and she saw some of this pinkish cast. I think maybe she had cut into it on her own, seeing some of that pinkish cast. So, she said she would like to look at that half of it, and we made some detectors out of it. Suddenly, we had a $D^{*}$ in the ten to the ninth, and it had the right $x$ value. Well that was very exciting then. We knew we were on to something pretty good.

We were in communication with the Honeywell Radiation Center in Lexington, Massachusetts at the time during this whole thing. They had been manufacturing indium antimonide detectors. Somewhere along the line, I can't remember when, probably in late '64, we gave them a $\mathrm{HgCdTe}$ detector, a liquid nitrogen temperature detector, a single element detector which they could compare with the indium antimonide detectors.

\section{Under the HRB Singer contract?}

Right, and HRB Singer got quite excited about it and gave the Honeywell Radiation Center a contract to develop an advanced version of the Mohawk Mapper. Mercury cadmium telluride was to be the detector in the advanced version. Honeywell Radiation Center got a contract to develop a single element, mercury cadmium telluride, liquid nitrogen temperature, photoconductive detector for the advanced version of the HRB Singer mapper.

\section{Pivotal Detector Meeting at NRL in Dec. 1964}

In December of 1964, there was a fairly significant meeting called by Henry Shenker at Naval Research Laboratory (NRL) for all the detector companies. Now, the established companies that were in the detector business were Santa Barbara Research Center of Hughes, and Texas Instruments. Other work was being done at RCA and Westinghouse. Honeywell was sort of an outsider in a certain sense. We didn't have much of an effort going really. We had the one air force contract at the Honeywell Corporate Research Center and the one contract with HRB Singer at the Honeywell Radiation Center.

The other established companies were basically working on the extrinsic germanium, mostly mercury-doped germanium. There was this meeting. It was to look at 8-12 $\mu$ m detectors. It was a classified meeting at the Naval Research Laboratory. We presented our data on the mercury cadmium telluride. I can remember that the efforts of the established extrinsic detector companies, mostly TI and Santa Barbara, were trying to put our work in disrepute basically. In other words, they said there was no future to mercury cadmium telluride and the real wave of the future lay in the mercury-doped germanium.
The services were represented, and the established extrinsic detector companies said that's where the services should put all their money, in mercury-doped germanium, not this mercury cadmium telluride. Mercury-doped germanium detectors at that time had a detectivity of maybe a factor of ten higher or something like that. They were starting to make arrays of them. Of course, they were long thin columns sticking up because of the low absorption coefficient. But they believed that and they were trying to beat our work.

Well, anyway, it didn't do them any good. We continued to work on it, continued to get contract support. DARPA became interested, and we got a DARPA contract, I think in about ' 65 . We then had two contracts. We had an air force contract and a DARPA contract. The air force contract kept on for many years and various versions.

\section{Transfer of HgCdTe Technology to the Honeywell Radiation Center Began in 1965}

We were always interested in trying to transfer technology out of the Corporate Research Center to the Honeywell Radiation Center. In late 1964, early 1965, Ray Russell from the Radiation Center came out to the Research Center and spent a week with us and learned how to prepare sensitive elements from pieces of mercury cadmium telluride, single elements, how to lap and polish the material.

These early detector elements had soldered leads. We were mounting them on, I think, germanium substrates. There was a question of how you make the Dewar too. The Dewar was a single element Dewar, liquid nitrogen temperature, standard style, with the Kovar weld rings, but we had to find a new window. We had spent quite a bit of time looking at window materials... germanium, synthetic sapphire, some of the Irtran materials that were just coming out at that time ... and window-sealing techniques. We were epoxying them down, but that was not thought to be a very good method. You really wanted to have a glass-to-glass seal, a standard procedure like that. We were looking at frets for putting between the window material and the barrel of the housing. So, there was work going on in the detector Dewar fabrication area too under the contract.

Ray Russell came out, in I think probably '65, early '65, and spent a week with us and took back to the Radiation Center these methods of making the detector elements and making the Dewars. We started supplying material to the Radiation Center. Jack Lennard was head of the Detection Sciences Group at the Radiation Center at the time. I think we gave the Radiation Center most of the good part, the back...it was 50-100 mm...of Ingot 6-1864 at the time. Jack Lennard coined the term "tenderloin" for that. Supposedly it was locked up in a safe. 


\section{High-Temperature Anneal Becomes Standard Part of HgCdTe Crystal Growth Process}

After we realized that this accident, which made good detectors, had resulted in high-temperature anneal, and we learned right away that the dendrites were gone from that annealed region, we immediately then began to do a compounding step followed by an annealing step in the Marshall Products furnace. Compound in the rocking furnace, take the ampule out, place the ampule in the Marshall Products furnace and, instead of dropping it through a freezing plane, simply heat it up to $650^{\circ}$ and let it sit there. That was a lot better.

We had this lowering mechanism which was an old drill press stand. We had the water underneath it. It was very difficult to do that. This compound/ anneal procedure turned out to be a much simpler thing. Somewhere along the line, we realized that $20 \%$ was a better estimate than $10 \%$ for the 8-12 $\mu \mathrm{m}$ material. We knew that, and we were then annealing the material instead of trying to lower it through a freezing plane, through the high-temperature anneal.

Some of the other stuff was beginning to fall into line. We were beginning to get parts of the material that were sufficiently uniform so we could begin to make sense out of some of the Hall effect data and other electrical data. We began to get numbers for mobilities that we had some confidence in, particularly for $n$-type material. $P$-type material still, of course, had a lot of problems with interpretation of electrical data. It wasn't until Walter Scott came to work at the Research Center and began to look at it that $p$-type material began to be better understood. In '69 he came up with the idea of lightly doped $p$-type material, where it actually had an $n$-type skin. That then began to explain some of these really strange effects we'd been looking at in the $p$-type material.

We began to get numbers for majority carrier lifetime from frequency response measurements for the photoconductive signal. In '65, '66, '67, we began to get a much better understanding of the material.

In 1964, I got a second contract, a completely different contract from the army, on what was called a thin-film image converter. Dick Schulze came to work for Honeywell about 1963, and he and I worked together on this contract. So I was working on two contracts in '64 and '65. The army contract required a quarterly report, and the air force a monthly letter and a quarterly report, or vice versa, so I spent an awful lot of time writing reports. It was very aggravating, all the report writing.

I was dividing my time between these two contracts. In '65, I think, Joe Schmit, I don't remember the exact sequence, but basically, Joe took over the direction of the effort in about' 65 .

It was somewhere around that time that I remember talking to Don Long and listing all the possible things we could publish, in principle, that we had enough information to publish on. Don, I think, was the department manager by then. What happened was Don McGlauchlin got promoted. He became an Assistant Director of the laboratory, Assistant Director of Research.

I was asked to take over that department. I said I would rather not, since I by that time was a staff scientist and I felt at the time, I preferred to do that. They had this dual-ladder structure, whereby supposedly you could get promoted up that side, about equally well as the other side. Supposedly, the perks and everything like that on both sides were equivalent. I emphasize the word supposedly. I told them I'd rather not become the department manager, and Don Long became the department manager. Called acting, but he was acting for a long time.

I wrote this memo to Don Long where I listed all the possible things we could publish, and we discussed it. It was decided that a lot of that material, even though maybe unclassified, was proprietary. The only thing I could publish was the paper ${ }^{30}$ that I did publish in Applied Optics which was a special issue, if I recall, devoted to infrared technology. Later on that situation eased up a lot. The secrecy order was removed from the air force contract. After Joe got well into it, they allowed him to publish a lot of the stuff. ${ }^{31-33}$ Then Warren Saur published a paper $^{34}$ in '67 or so, in which he showed a photoresponse at helium temperature going out to $40 \mu \mathrm{m}$ for a low- $x$ material like $17 \%$ or $18 \%$.

\section{Don Long Systematically Analyzed Funda- mental Mechanisms in Infrared Detectors}

When did Don Long begin to get involved with mercury cadmium telluride?

I think it was after he became the department manager, which was 1965 . He always did things other than pure management. He was always spending maybe $25 \%$ of his time doing technical work. He was not doing laboratory work, but he was doing analyses. After he got to be manager of a group whose responsibility was basically electrooptical effects, I think probably called Electro Optics department at that time, most of the things going on were related to infrared detectors.

Don Long started a series of seminars. He was doing his own analysis. He'd start it from very, very basic ideas and build up a body of knowledge in his own mind which he was publishing in these seminars. Others of us were giving parts of the seminar too, but he was building up the whole idea of how infrared detectors work, and others were contributing to it too. He was developing his own feel for this whole thing. ${ }^{16,17}$

Of course, Don had been a solid state physicist, so the solid state part of it came naturally to him, but the photo effects part was something new to him. The whole business of the background limit and things like this, and the competition between recombination mechanisms, and intrinsic versus 
extrinsic, and so on. He started publishing in this area in about '68 or ' $69 .{ }^{16,17,35-37}$

Walter Scott came aboard and he started working in this area too. He originally tried to look for photoemission from a piece of mercury cadmium telluride by optically pumping it. If it's radiative limited, you should see that radiation. He was UV pumping and looking with a spectrometer. He was never able to see anything.

\section{HgCdTe Gained Momentum at Both the Research Center and the Radiation Center}

After about '65, the whole thing gathered an awful lot of momentum. The Radiation Center became very much more involved with the Research Center. The efforts at the both the Research Center and the Radiation Center greatly expanded.

Bob Lancaster grew his first crystal here at the Radiation Center in 1967.

Yes. We transferred the crystal growth technology in '67, and transferred the detector fabrication technology in '65. A lot of people got involved with it at the Radiation Center. The Radiation Center began to gather up a lot of momentum. Our effort at the Research Center became a little bit larger, but very quickly you surpassed us in terms of the number of people working on it. We began, at the Research Center, to get other contracts. Joe Schmit was basically the guy that was the principal investigator, and he began to look at other wavelength regions, such as shorter wavelengths.

A lot of interest in $3-5 \mu \mathrm{m}$. The fundamental studies part got a lot more expanded. We got the FTS spectrometer. Walter Scott ran that. He began to look at the optical absorption in the material. ${ }^{38}$ Ernie Stelzer got involved with it. Obert Tufte got involved in 1966 or '67. Obert was a staff scientist, and we got a contract from ARPA, I think, to try to develop an epitaxial method of growth. Obert was working with Ernie Stelzer, and they worked on this so-called close space transport method ${ }^{39}$ in a sealed tube where you had the source piece and the cadmium telluride substrate very close to each other. You heat them up in a furnace and you get some source material transporting over to the substrate. They began to make layers there, which it turned out were very uniform laterally, but very nonuniform away from the surface, but otherwise they were working on that in ' 67 and ' 68 , in that time frame.

It takes a long time before you can transfer a technology, and there weren't that many examples of things that were transferred out of the Research Center. When we transferred the mercury cadmium telluride detector technology to the Radiation Center in '65, that was looked upon very favorably, and I got a H. W. Sweatt award ${ }^{40}$ for that. That was awarded in '66, which was the first year. There were three Sweatt awards given out of our laboratory in 1966 for work done in '65.
You can see that there must have been a pretty positive attitude at that time toward the work, because it was something that was beginning to pay off basically, for our laboratory. There were other things that were being done there too, a lot of good magnetics work that was paying off to the Honeywell Avionics Division in Florida, such as magnetic plated wire memory. It was looked upon quite favorably.

\section{HgCdTe Rapidly Gained Acceptance in the Army Common Module FLIR Applications}

\section{When did you join the Army Scientific Advisory Panel?}

1965. All along, of course, the mercury cadmium telluride technology was proceeding and becoming more and more entrenched. And, once you got the idea of the common module FLIR (forward-looking infrared), which was developed... TI began to develop that in the early 1970 s under contract.

Once the army began to see the first FLIRs, they just fell wildly in love with them. The army, I mean the users, the important people who are out there using the equipment, and they're the people that can, say, go back and say to Development and Readiness Command (DARCOM), the developer, "Hey, that stuff is just marvelous." Once you began to see that, then you knew that this whole thing was going to take off. Not only that, but you knew mercury cadmium telluride was then very deeply entrenched. Not only that, but you knew that secondgeneration technology was a long way off, a long way off from a user point of view. Might be fairly close to being here from a technology point of view but, if you understand the way that the army system works, in which you go through all these army systems acquisition review councils (ASARCs) and defense systems acquisition review councils (DSARCs) to get something, a product, and it takes close to 10 years to get the product out in production.

The so-called IOC, initial operational capability, typically takes 10 years, and the thing stays in production for at least 10 years, 10 or 15 years. The way that changes are made is not to throw away something and replace it but rather product-improve it. It happens in all major weapon systems, and you begin to adopt the point of view that says that when you've got billions of dollars invested in this FLIR technology, common module FLIR technology, there's no way that you're going to make stepwise changes. You can only make product improvement type of changes.

This means that it's very hard to introduce secondgeneration technology, which is staring arrays ... I'm talking about staring array technology... into those existing FLIR night vision applications. Second-generation technology really belongs in missile seekers and sensor fused munitions where you don't have an existing product that you have to displace. Rather now, you've expanded the applications sphere and now you've got a new application and you're looking at something maybe that will not be put into pro- 
duction until 1985 time frame and therefore you can ... maybe later than that. Therefore, you can make your decisions now as to the best available technology. You don't have to displace anything.

So that's I think where second generation's going to fit.

\section{APPENDIX}

\section{Germanium Free Carrier Infrared Modulator}

About late 1958-1960 I was working on the germanium free carrier modulator. I don't know if you ever remember that. That became a Honeywell product too. I sold one.

I got interested then, after I finished with the PEM cell, in this idea of modulating infrared radiation. You take a rectangular parallelepiped of germanium, and it's $n$-type germanium. This is maybe an inch, maybe half an inch long, by an eighth of an inch in cross-section.

On one of the long faces, then, you put an indium contact, an indium alloy contact, and you get a $p-n$ junction down below the indium a little bit. Now, you can inject, if your doping profile is correct, you inject holes, forward biasing injects holes into the $n$-type region. The holes have a very high cross-section for free carrier absorption. So the material, even though it's half an inch to an inch long in the direction you shine light through it, the long dimension, is fairly transparent when it's just got the free electrons in it, but when you inject the holes it shutters, it basically becomes much more opaque. It's not free-carrier absorption, I think it's intra-valence band absorption.

It becomes much more opaque. I was always applications oriented, so we began to look at a communication system.

That communication system consists of a light bulb, which was a projection lamp from a slide projector with a built-in reflector, and focused radiation on the end of this little bar. Then we had a microphone, the microphone output went to a preamp and then a power amplifier. The output of the power amplifier was this little diode, a big diode. Then it gave you a rectified waveform in effect. That sent out a modulated light that came out of the end of that, modulated infrared radiation. Then if you had another one of these devices with a lead sulfide cell in it, you could pick up that modulated voice.

We had a speaker at the output of it, so you could communicate. We made a pair of transceivers. We had a mirror that we could move into that radiation path. The mirror was up out of the way when you talked, and when you listened, the mirror came down and reflected the incident radiation on to the lead sulfide detector.

This had about a three-kHz bandwidth, which is good for voice. We could talk over a distance of a mile or two, mile and a half maybe. I was doing that in the 1958-1960 time frame. That was transferred out to a Honeywell division in West Los Angeles and became a Honeywell product, but it didn't sell at all; they sold one, I think, or something like that. It was called MAXECOM. My technician, Bill Farber, named it maximum security communication, MAXECOM. That Honeywell division was desperately looking for infrared detection and infrared technology products, and they grabbed that right away, plus the PEM cell.

There were people looking at infrared communications by various means. In World War II you had infrared communications too, and they were by modulated xenon lamps and things like that.

The navy was interested in ship-to-ship secure communications. You had a better geometry there, you didn't have any hills or anything in the way.

After I finished with the free-carrier modulator work, I did some work on cadmium sulfide on a PhotoPot, a photosensitive potentiometer, about 1960 with Jim Garfunkel. That was a small effort supported by the Avionics Division. We worked on that for 6 months and made a prototype of a photosensitive potentiometer using cadmium sulfide as the optically active element.

\section{REFERENCES}

1. Proc. SPIE 7298, 72982M (2009).

2. T. Elliott, Proc. SPIE 7298, 72982M (2009).

3. M.B. Reine, Proc. SPIE 7298, 7298-2S (2009).

4. J. Schmit, P. Kruse, and E. Stelzer, Proc. SPIE 7298, 72982R (2009).

5. E. Putley, Chapter 7 in Cold War, Hot Science: Applied Research in Britain's Defence Laboratories 1945-1990, 1st ed., ed. R. Bud and P. Gummett (London: Harwood Academic Publishers, 1999), pp. 185-218.

6. W.D. Lawson, S. Nielsen, E.H. Putley, and A.S. Young, J. Phys. Chem. Solids 9, 325 (1959).

7. W.D. Lawson, S. Nielsen, and A.S. Young, UK patent 859,588 (Application Date 3 September 1957; Published 25 January 1961).

8. W.D. Lawson, S. Nielsen, and A.S. Young, U.S. patent 2,953,690 (Filed 3 September 1958; Patented 20 September 1960).

9. P.W. Kruse, L.D. McGlauchlin, and R.B. McQuistan, Elements of Infrared Technology: Generation, Transmission and Detection (New York: Wiley, 1962).

10. U.S. Air Force Contract AF33(616)-7901, Performed at Honeywell Research Center, Hopkins, Minnesota; P.W. Kruse, Principal Investigator; T.D. Pickenpaugh, Air Force Technical Monitor.

11. P.W. Kruse, M.D. Blue, J.H. Garfunkel, and W.D. Saur, Infrared Phys. 2, 53 (1962).

12. M.D. Blue and P.W. Kruse, Proceedings of the Black Hills Summer Conference on Transport Phenomena, 21-23 August 1962, South Dakota School of Mines, Rapid City, South Dakota, pp. 205-218 (1962). DTIC Document AD0289290, http://www.dtic.mil/cgi-bin/GetTRDoc?AD=AD0289290\& Location $=\mathrm{U} 2 \&$ doc $=$ GetTRDoc. . pdf.

13. M.B. Reine, P.R. Norton, and E.L. Stelzer, Proc. SPIE 8704, $87041 \mathrm{~F}(2013)$

14. M. Reine, J. Electron. Mater. 42, 3001 (2013).

15. S.R. Borrello and H. Levinstein, J. Appl. Phys. 33, 2947 (1962).

16. D. Long, Infrared Phys. 7, 169 (1967).

17. D. Long, Infrared Phys. 7, 121 (1967).

18. C. Hilsum and I.M. Ross, Nature 179, 146 (1957).

19. P.W. Kruse, J. Appl. Phys. 30, 770 (1959).

20. T.J. Davies, J. Appl. Phys. 28, 1217 (1957). 
21. J.S. Blakemore, D. Long, K.C. Nomura, and A. Nussbaum, Progress in Semiconductors, Vol. 6, ed. A.F. Gibson (London: Heywood \& Company Ltd, 1962), pp. 39-84.

22. J.S. Blakemore, Semiconductor Statistics (Oxford: Pergamon Press, 1962).

23. R.L. Petritz, Photoconductivity Conference, ed. R.G. Breckenridge, B.R. Russell, and E.E. Hahn (New York: Wiley, 1956), p. 49.

24. E.S. Rittner, Photoconductivity Conference, ed. R.G. Breckenridge, B.R. Russell, and E.E. Hahn (New York: Wiley, 1956), p. 215.

25. R.L. Petritz, Proc. IRE 47, 1458 (1959).

26. M.D. Blue and P.W. Kruse, J. Phys. Chem. Solids 23, 577 (1962).

27. M.D. Blue, J.H. Garfunkel, and P.W. Kruse, J. Opt. Soc. Am. 51, 1408 (1961).

28. D.R. Morey and S. Sheldon, U.S. patent 3,239,675 (8 March 1966).

29. J. Blair and R. Newnham, Metallurgy of Elemental and Compound Semiconductors, Vol. 12 (New York: Wiley Interscience, 1963), p. 393.

30. P.W. Kruse, Appl. Opt. 4, 687 (1965).
31. D. Long and J.L. Schmit, Chapter 5 in 'Semiconductors and Semimetals, Vol. 5, ed. R.K. Willardson and A.C. Beer (New York: Academic Press, 1970), .

32. P.W. Kruse, D. Long, and O.N. Tufte, Proceedings of the Third International Conference on Photoconductivity, Stanford University, 12-15 August 1969, ed. E.M. Pell (New York: Pergamon Press, 1971), pp. 223-229.

33. J.L. Schmit and E.L. Stelzer, J. Appl. Phys. 40, 4865 (1969).

34. W. Saur, Infrared Phys. 8, 255 (1968).

35. D. Long, Chapter 4 in Topics in Applied Physics: Optical and Infrared Detectors, ed. R.J. Keyes (Berlin: Springer, 1980), pp. 101-147.

36. D. Long, Phys. Rev. 176, 923 (1968).

37. D. Long, Energy Bands in Semiconductors (New York: Wiley, 1968).

38. M.W. Scott, J. Appl. Phys. 40, 4077 (1969).

39. O.N. Tufte and E.L. Stelzer, J. Appl. Phys. 40, 4559 (1969).

40. The "H.W. Sweatt Engineer-Scientist Award" was presented annually to recognize outstanding technical accomplishments throughout the Honeywell company. It was named after Harold W. Sweatt, a longtime president of Honeywell. 